\title{
Welfare state of dairy cows in three European low-input and organic systems
}

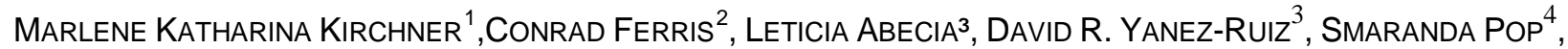 \\ ILIE VOICU ${ }^{4}$, CATALIN DRAGOMIR ${ }^{4}$, CHRISTOPH WINCKLER ${ }^{1}$
}

Key words: animal welfare, Welfare Quality, assessment system, critical points, injuries, pasture

\begin{abstract}
Animal welfare in organic and low-input dairy cow systems is commonly expected to achieve at least satisfactory levels. This assumption is based on the regulations regarding housing and management of the animals and/or the access to pasture. The aim of the present study was to evaluate 30 dairy farms in three European countries using the Welfare Quality ${ }^{\circledR}$ assessment protocol in order to characterize these systems and evaluate whether expectations regarding the state of welfare are met. Farms were found to have mainly an acceptable and enhanced overall welfare state. In general, weak points found related to the presence of injuries and discomfort of the lying areas of the cows. In some countries, specific problems such as mutilations, poor human-animal relationship or insufficient water provision were identified. Variation between farms showed that on one hand farms could benefit from intervention studies and on the other hand that good and even excellent results are possible in organic and low-input dairy systems.
\end{abstract}

\section{Introduction}

Low-input and organic dairy systems are known to be managed differently than intensive and conventional production units. Sustainability aspects of these systems are often pointed out and discussed (Leach, 2012). Especially the fact that pasturing is frequently used in these systems is perceived as more animal friendly (Reijs et al., 2013), but only limited information is available on the welfare of dairy cows in low-input systems. In recent years, comprehensive, mostly animal-based on-farm welfare assessment systems have been developed. For example, the Welfare Quality ${ }^{\circledR}$ (WQ) assessment protocol combines a range of animalbased measures and information on management and resources (Welfare Quality ${ }^{\circledR}, 2009$ ). The data are collected during on-farm visits and can be used for providing feedback to the farmer on the welfare state as a basis for improvement (Gratzer, 2011). The single measures are further aggregated into twelve criteria and four principle scores. An overall classification may also be obtained for the farm. The aim of this study was therefore to apply the WQ protocol to low-input and organic dairy production systems in three European countries in order to evaluate the welfare state of the dairy cows in these systems.

\section{Material and methods}

Ten low-input and/or organic dairy farms each in Northern Ireland (NI), Romania (RO) and Spain (SP) were assessed in the late winter and early spring of 2013 using the WQ assessment system (Welfare Quality, 2009). The farms were identified by local research partners and farming associations. Scores for twelve WQ criteria and four WQ principles were calculated from the measures according to the WQ protocol. They may range from 0-100 (poor-good, with a score of 50 indicating a somewhat 'neutral' situation). For the identification of welfare problems, we applied a threshold of 40 .

\footnotetext{
${ }^{1}$ contact details: University of Natural Resources and Life Sciences, Vienna, Austria, www.boku.ac.at, eMail marlene.kirchner@boku.ac.at.

${ }^{2}$ Sustainable Dairy Systems, Agri-Food and Biosciences Institute, Largepark, Hillsborough, Great Britain, http://www.afbini.gov.uk, conrad.ferris@afbini.gov.uk

${ }^{3}$ INAN, Estación Experimental del Zaidín (CSIC), Granada, Spain, http://www.eez.csic.es, david.yanez@eez.csic.es

${ }^{4}$ INCDBNA, IBNA-Balotesti, Ilfov, Romania, http://www.ibna.ro, drg_catalin@yahoo.com
} 
Table 1: Mean \pm standard deviation (SD) of Welfare Quality principle (in italics) and criterion scores in the three farming systems investigated.

\begin{tabular}{|c|c|c|c|c|}
\hline \multirow{2}{*}{$\begin{array}{l}\text { WQ } \\
\text { Principle }\end{array}$} & \multirow{2}{*}{ WQ Criterion } & Northern Ireland & Romania & Spain \\
\hline & & \multicolumn{3}{|c|}{ Mean \pm SD } \\
\hline \multicolumn{2}{|c|}{ Good feeding } & $35.9 \pm 31.7$ & $51.2 \pm 26.1$ & $61.3 \pm 16.5$ \\
\hline & $\begin{array}{l}\text { 1. Absence of } \\
\text { prolonged hunger }\end{array}$ & $86.2 \pm 23.1$ & $41.8 \pm 27.3$ & $50.6 \pm 16.6$ \\
\hline & $\begin{array}{l}\text { 2. Absence of } \\
\text { prolonged thirst }\end{array}$ & $33.8 \pm 41.9$ & $83.5 \pm 35.5$ & $90.0 \pm 21.6$ \\
\hline \multicolumn{2}{|c|}{ Good housing } & $49.8 \pm 10.2$ & $50.2 \pm 15.6$ & $65.7 \pm 17.6$ \\
\hline & $\begin{array}{l}\text { 3. Comfort around } \\
\text { resting }\end{array}$ & $20.4 \pm 16.2$ & $42.2 \pm 27.5$ & $48.0 \pm 22.9$ \\
\hline & $\begin{array}{l}\text { 4. Thermal } \\
\text { comfort }\end{array}$ & $100.0 \pm 0.0$ & $71.1 \pm 16.6$ & $96.0 \pm 12.7$ \\
\hline & $\begin{array}{l}\text { 5. Ease of } \\
\text { movement }\end{array}$ & $100.0 \pm 0.0$ & $68.0 \pm 16.9$ & $96.0 \pm 12.7$ \\
\hline \multicolumn{2}{|c|}{ Good health } & $41.2 \pm 8.0$ & $43.5 \pm 17.0$ & $31.3 \pm 9.8$ \\
\hline & $\begin{array}{l}\text { 6. Absence of } \\
\text { injuries }\end{array}$ & $36.7 \pm 14.5$ & $34.9 \pm 15.9$ & $31.5 \pm 11.8$ \\
\hline & $\begin{array}{l}\text { 7. Absence of } \\
\text { disease }\end{array}$ & $71.7 \pm 17.6$ & $70.7 \pm 24.5$ & $58.7 \pm 21.0$ \\
\hline & $\begin{array}{l}\text { 8. Absence of } \\
\text { pain induced by } \\
\text { management } \\
\text { procedures }\end{array}$ & $38.6 \pm 10.5$ & $74.0 \pm 36.2$ & $26.4 \pm 28.6$ \\
\hline \multicolumn{2}{|c|}{ Appropriate behaviour } & $51.7 \pm 17.7$ & $49.5 \pm 21.8$ & $42.0 \pm 12.9$ \\
\hline & $\begin{array}{l}\text { 9. Expression of } \\
\text { social behaviours }\end{array}$ & $57.8 \pm 25.3$ & $75.4 \pm 26.8$ & $72.9 \pm 24.8$ \\
\hline & $\begin{array}{l}\text { 10. Expression of } \\
\text { other behaviours }\end{array}$ & $78.9 \pm 7.3$ & $64.0 \pm 24.2$ & $83.4 \pm 29.9$ \\
\hline & $\begin{array}{l}\text { 11. Good human- } \\
\text { animal } \\
\text { relationship }\end{array}$ & $54.3 \pm 20.3$ & $62.6 \pm 16.1$ & $27.7 \pm 8.0$ \\
\hline & $\begin{array}{l}\text { 12. Positive } \\
\text { emotional state }\end{array}$ & $53.8 \pm 22.5$ & $48.8 \pm 35.0$ & $58.8 \pm 27.3$ \\
\hline
\end{tabular}

\section{Results}

In five out of the 12 criteria the average score was below 40 in at least one country; at the principle level this was the case for 2 principles (Table 1). With regard to 'Good feeding' this was mainly due to an on average non-satisfactory water provision ('Absence of prolonged thirst': e.g. too few water points per animal, cleanliness of water points) in $\mathrm{NI}$, while body condition of the cows as a measure of 'Absence of prolonged hunger' was less of a problem. The average principle scores for Good Housing all exceeded the threshold of 40, but the criterion 'Comfort around resting' (referring to lying down movement and cleanliness of the animals) scored lowest in NI. The principle 'Good Health' scored rather low in all production systems, but especially in farms in Spain. At the level of the three corresponding criteria, 'Absence of injuries' which includes lameness and skin alterations was the weakest criterion for all countries. While 'Absence of disease' achieved on average high scores, in the criterion 'Absence of pain induced by management procedure' countries again differed markedly. Due to the dehorning and partly tail-docking practices $\mathrm{NI}$ and SP farms did not exceed the above mentioned threshold, whereas such procedures were much less frequent in RO.

In all countries, the threshold was exceeded for the 'Appropriate behaviour' principle, but in SP farms the criterion scores for 'Good human-animal-relationship' (resulting from avoidance distance testing at the feeding place) were low. At overall classification level half of the farms were graded as 'Acceptable', $43 \%$ achieved an 'Enhanced' welfare state and one farm was classified 'Excellent'; one farm ended was 'Not classified' (Figure 1). 


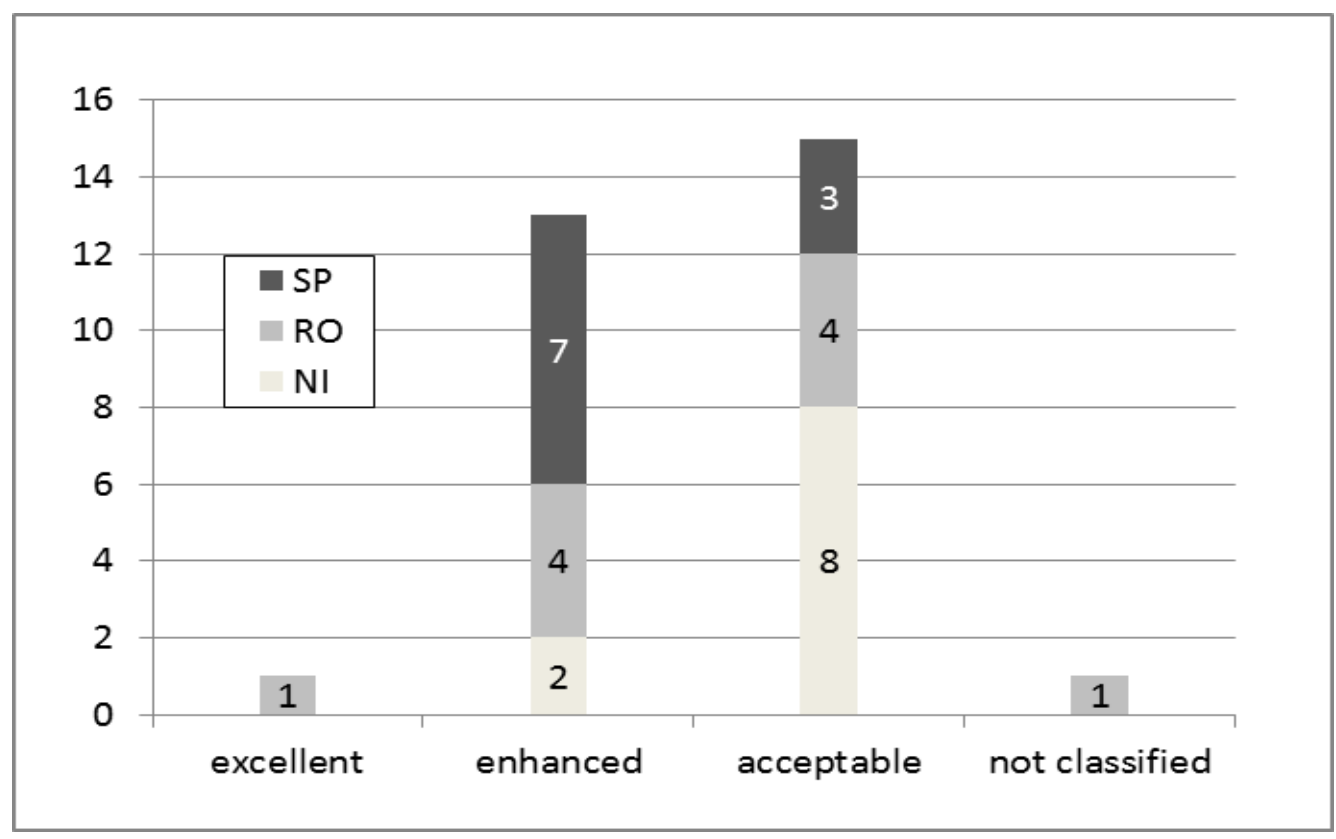

Figure 1. Number of farms in Northern Ireland, Romania and Spain within respective category of overall classification according to the Welfare Quality assessment system.

\section{Discussion}

Across the production systems investigated the presence of injuries in the cows may be regarded a general welfare problem. Furthermore, 'Comfort around resting' and 'Absence of pain induced by management procedures' were identified as unsatisfactory in at least two countries. 'Thermal comfort', 'Ease of movement', 'Absence of disease' as well as most of the criteria related to 'Appropriate behaviour' may be considered at least acceptable.

It was remarkable that even in the low-input systems investigated the criterion 'Other behaviour', which refers to access to pasture, did not achieve excellent scores (on average). This indicates that the amount of days and hours in a year spent on pasture regarded 'Excellent' by animal welfare experts (Welfare Quality, 2009) does not match with what can be found in at least some of the low-input farms in the present study. It remains open if the expert opinion regarding animal welfare is too ambitious or if this small sector of the dairy industry follows the general trend of reducing access to pasture as recently discussed by Reijs et al. (2013).

\section{Suggestions to tackle with the future challenges of organic animal husbandry}

In conclusion our results show that the expectations regarding a very high state of animal welfare were not met at least for half of the investigated farms. There were some common, major problem areas across countries and some were only country-specific. This proofed that there is room and need for improvements and implementation of intervention measures are highly recommended. Nonetheless a substantial part of the farms demonstrated that an 'enhanced' or even 'excellent' state of animal welfare is possible in low-input and/or organic systems.

\section{Acknowledgements}

The research leading to these results has received funding from the European Community's Seventh Framework Programme (FP7/ 2007-2013) under the grant agreement n FP7-266367 (SOLID).

\section{References}

Gratzer ET 2011. Animal health and welfare planning in Austrian organic dairy farming. Doctoral thesis. University of Natural Resources and Life Sciences (BOKU), Vienna.

Leach K 2012. Assessing the sustainability of EU organic and low input dairy farms. Organic Research Centre Bulletin $111,9-10$. 
Reijs JW, Daatselaar CHG, Helming JFM, Jager J and Beldman ACG 2013. Grazing dairy cows in North-West Europe Economic farm performance and future developments with emphasis on the Dutch situation. In LEI Report 2013-001 (Ed. LCv Staalduinen), p. 126. LEI Wageningen UR, The Hague.

Welfare Quality ${ }^{\circledR} 2009$. Welfare Quality ${ }^{\circledR}$ assessment protocol for cattle. Welfare Quality(R) Consortium, Lelystad, Netherlands. European Commission (2007): A new health strategy for the European union (2007-2013) where "Prevention is better than cure", Bruxelles, 26p 